Initial and follow up data on 20 young females with ketoacidotic brittle diabetes. Iralues are mean (SD) unless stated otherwise

\begin{tabular}{lccc}
\hline & $\begin{array}{c}\text { Initial assessment } \\
(1979-85)\end{array}$ & $\begin{array}{c}\text { Follow up } \\
\text { assessment } \\
(1989)^{\star}\end{array}$ & p Value \\
\hline No of subjects & $\begin{array}{c}20 \\
\text { Age (years) }\end{array}$ & 18 & \\
Iuration of diabetes (vears) & $7 \cdot 7(4 \cdot 1)$ & $26 \cdot 6(4 \cdot 4)$ & \\
Weight $(\mathrm{kg})$ & $64 \cdot 4 \cdot 2)$ & $15 \cdot 7(4 \cdot 4)$ & \\
Insulin dose (units/day) & $145(46)$ & $65 \cdot 6(8 \cdot 3)$ & $\mathrm{NS}$ \\
No injecting insulin: & 14 & $69(18)$ & $<0 \cdot 005$ \\
$\quad$ Subcutaneously & 4 & 16 & \\
$\quad$ Intramuscularly & 2 & 2 & \\
$\quad$ Intravenously & $14 \cdot 1(3 \cdot 4)$ & $13 \cdot 5(4 \cdot 2)$ & $\mathrm{NS}$ \\
Glycated haemoglobin (\%) & $14 \cdot 5(10 \cdot 2)$ & $1 \cdot 9(2 \cdot 9)$ & $<0 \cdot 001$ \\
No of hospital admissions in & $0(0)$ & $6(33)$ & $<0 \cdot 02$ \\
$\quad$ past year & & & \\
No (\%) with complications & & & \\
\hline
\end{tabular}

$\star$ Follow up was for a mean of $8 \cdot 2$ years.

pancreatic segmental transplant, which had failed. The clinical characteristics of the patients provided no explanation for their resistant instability.

\section{Comment}

Little is known of the natural course of brittle diabetes. In a three to six year follow up of 13 patients, most of whom were young females with recurrent ketoacidosis, one patient died of hypoglycaemia and the rest generally improved..$^{2}$ Admissions to hospital were reduced, but 11 of the 12 survivors were still considered brittle at follow up. Tattersall et al reported that brittleness had resolved in five of 11 patients with ketoacidotic brittleness at 12 years' follow up; one patient had died and one was lost to follow up.

Combining our results with those of the above studies gives a total of 43 patients, four $(10 \%)$ of whom died. Though this mortality seems high for predominantly young patients, data from the Pittsburgh study suggest that about a $95 \%$ survival would be expected in patients who have had diabetes for 15 years. ${ }^{+}$Our rate of complications of $33 \%$ compares favourably with that found by Pirart, who reported retinopathy in $45 \%$ of patients with diabetes of 16 years' duration. The complications and mortality associated with brittle diabetes are thus not excessive compared with those in other diabetic patients.

Although a "hard core" of patients may continue to present serious problems, there seems to be a strong tendency for brittle diabetes to improve or resolve, with insulin doses and hospital admissions falling during follow up. Though we have no hard data, resolution in at least some cases seems to coincide with positive life events such as marriage, pregnancy, or forming a stable relationship. The difficulties of controlling diabetes in adolescence are well known, and brittle diabetes may represent an extreme response to psychosocial disruption or teenage rebellion, or both.

We thank the staff of the Freeman Hospital Diabetes Unit and the consultants caring for the patients described in this paper. We also thank Drs S Walford, S Marshall, P Home, D Husband, and R Taylor for their help.

1 Gill GV, Home PD, Massi-Benedetti M, Pernet A, Canaldo D, Burrin JM, et al. Clinical and metabolic characteristics of patients with brittle diabetes. Diabetologia 1981:21:507.

2 William G, Pickup JC. The natural history of brittle diabetes. Diabetes Res 1988;7:13-8.

3 Tattersall R, Gregory R, Selby C, Kerr D, Heller S. Course of brittle diabetes: 12 year follow up. $B M \mathcal{F} 1991 ; 302: 1240-3$.

+ Dorman JS, Laporte RE, Kuller LH, Cruickshank KJ, Orchard TJ, Wagener DK, et al. The Pittshurgh insulin-dependent diabetes mellitus (IDDM) morbidity and mortality study. Mortality results. Diabetes 1984;33:271-6.

5 Pirart J. Diabetes mellitus and its degenerative complications: a prospective study of 400 patients observed between 1947 and 1973. Diabetes Care 1978:1:168-88

(Accepted 4 fulv 1991 )

\title{
Reuse of disposable plastic insulin syringes
}

\section{B Miles Fisher, Charles Heatley, Michael Small}

Diabetic Clinic, Gartnavel General Hospital, Glasgow G12 0YN

B Miles Fisher, MD, senior registrar

Charles Heatley, MRCP, registrar

Michael Small, MD, consultant physician

Correspondence to: Dr B Miles Fisher, Ward 4/5, Royal Infirmary, Glasgow G4 OSF.

$B M \mathcal{1}$ 1991;303:286-7
When disposable plastic insulin syringes became available on prescription in September 1987 the Department of Health and Social Security insisted that they should be used once only. This was despite the advice of the British Diabetic Association' and the evidence of studies which showed reuse to be safe. ${ }^{2-4}$ In November 1987 we performed a survey of the use of disposable syringes in our diabetic clinic. ${ }^{5}$ The present study was to see whether the frequency of reuse of disposable plastic insulin syringes had changed over the subsequent three years.

\section{Patients, methods, and results}

Patients were questioned again in August 1990 by means of an identical postal questionnaire. In the intervening three years no further advice about the reuse of syringes had been given to the patients. Statistical analysis was by Wilcoxon's signed rank test and Student's $t$ test for paired data.

Of the 103 patients who had completed the survey in 1987, nine had died and eight had moved out of the area. The questionnaire was distributed to the remaining 86 patients and was completed and returned by $65(76 \%)$. The mean number of injections that each syringe was used for had increased significantly from
$5 \cdot 6($ SEM $0 \cdot 5)$ to $7 \cdot 1(0 \cdot 7)$ (table). There was no change in the treatment regimen, and the prescription size was similar. The mean duration of use of each syringe had increased significantly from $3 \cdot 2(0 \cdot 3)$ days to $4 \cdot 3(0 \cdot 6)$ days, and the length of time served by each prescription had increased significantly from 170 (26) to 231 (38) days. Patients were asked if they used each syringe more often, less often, or the same number of times as in 1987. Sixteen patients $(25 \%)$ had not changed the number of injections per syringe, 29 patients (45\%) had increased the number of injections per syringe, and 20 patients $(31 \%)$ were using the syringe for fewer injections. Twenty three of the 29 patients who had increased the reuse of syringes believed that their use was unchanged.

\section{Comment}

When plastic syringes became available on prescription the DHSS did not accept the advice of the British

Use, reuse, and prescription of disposable plastic syringes. Values are means (SEM) [range]

\begin{tabular}{lccc}
\hline & 1987 & 1990 & Significance \\
\hline $\begin{array}{c}\text { No of injections/ } \\
\text { syringe }\end{array}$ & $5 \cdot 6(0 \cdot 5)[1-14]$ & $7 \cdot 1(0 \cdot 7)[1-30]$ & $\mathrm{p}<0 \cdot 05$ \\
$\begin{array}{c}\text { No of injections } \\
\text { daily }\end{array}$ & $1 \cdot 8(0 \cdot 1)[1-2]$ & $1 \cdot 8(0 \cdot 1)[1-2]$ & $\mathrm{NS}$ \\
$\begin{array}{c}\text { No of syringes } \\
\text { prescribed } \\
\begin{array}{c}\text { No of days' use of } \\
\text { each syringe }\end{array}\end{array}$ & $55(5)[10-200]$ & $58(5)[10-200]$ & $\mathrm{NS}$ \\
$\begin{array}{c}\text { No of days' use } \\
\text { of each } \\
\text { prescription }\end{array}$ & $170(26)[10-1400]$ & $231(38)[10-1600]$ & $\mathrm{p}<0.05$ \\
\hline
\end{tabular}


Diabetic Association on reuse and insisted that they should be used only once. 'Diabetic patients therefore received conflicting advice from the DHSS and high street chemists (who had an added financial incentive in advocating the single use of syringes) on the one hand, and from diabetic clinic staff on the other. Our present study shows that patients heeded the advice of clinic staff and continued to reuse syringes. Indeed, the frequency of reuse of syringes by these patients actually increased. No systematic advice was given to the patients and there is no obvious reason why the reuse of syringes increased over time. One possible explanation is that patients increased the reuse of syringes as their confidence and experience grew. This did not seem to be a conscious decision as most patients were unaware that they had increased their frequency of reuse. The conflict should now be resolved as the Department of Health has recently issued Drug Tariff Specification No 39A bearing the heading "Sterile Single Use or Single Patient Use," although it seems likely that the labels on the syringes will continue to read "For single use only." 1 Alexander WD, Tattersall R. Plastic insulin syringes: reuse or waste \&8m a year.
BMF 1988:296:877-8.

2 Strathclyde Diabetic Group. Disposable or non-disposable syringes and needle for diahetics? BMF 1983;286:369-70.

Lester $\mathbf{E}, W_{\text {oodroffe }}$ FJ, Grant AJ. Experience with routine reuse of plastic insulin syringes. $B M \mathcal{F}$ 1984:289:1498-9.

4 Bloom A. Syringes for diabetics. BMF 1985;290:727-8.

5 Heatley C, Fisher BM, Small M. Prescription and use of disposable plastic insulin syringes. Practical Diabetes 1990:7:33-4.

(Accepted 6 fune 1991)

\title{
Effects of parathyroid hormone on delayed renal allograft function
}

\author{
C J Ferguson, J D Williams, Anne Silver, \\ J S Woodhead, J R Salaman
}

\section{Department of Surgery and Institute of Nephrology, Royal Infirmary, Cardiff CF2 1SZ \\ C J Ferguson, FRCS, research fellow \\ $\mathrm{J} \mathrm{D}$ Williams, $\mathrm{MD}$, reader in nephrology \\ J R Salaman, MCHIR, \\ professor of surgery}

Department of Medical

Biochemistry, University of Wales College of Medicine, Cardiff CF4 4XN

Anne Silver, PHD, research assistant

J S Woodhead, MRCPATH, reader in endocrine

biochemistry

Correspondence to: $\mathrm{Mr}$ Ferguson.

BMf 1991;303:287-8
Patients with chronic renal failure frequently have hyperparathyroidism. It has been suggested that high concentrations of circulating parathyroid hormone may result in an increased rate of delayed renal allograft function. ' We have investigated this relation in a prospective study using an assay for intact parathyroid hormone.

\section{Patients, methods, and results}

We studied patients receiving a cadaveric renal allograft between April 1988 and September 1989. Each received cyclosporin $10 \mathrm{mg} / \mathrm{kg}$ with or without other immunosuppressive agents. Blood samples were obtained before surgery and assayed with a two site immunochemiluminescence technique to measure intact parathyroid hormone ${ }^{2}$ (reference range $0 \cdot 9$ $5 \cdot 4 \mathrm{pmol} / \mathrm{l}$ ). Delayed function was defined as the requirement for dialysis or failure of the graft to reduce the serum creatinine concentration by $15 \%$ within four days of transplantation without technical failure or accelerated rejection. Statistical significance was assessed by the $\chi^{2}$ test and Mann-Whitney U test.

Eighty four patients received a cadaveric renal allograft, 18 of whom suffered delayed function. None of the grafts failed for technical reasons or as a result of

Recipient and donor data and other factors. Figures are medians (quartile deviation; 95\% confidence interval) and numbers of patients

\begin{tabular}{|c|c|c|}
\hline & Immediate function $(n=66)$ & Delayed function $(n=18)$ \\
\hline Recipient age (years) & $44(11 \cdot 5 ; 39 \cdot 1$ to $45 \cdot 6)$ & $38(15 ; 29 \cdot 8$ to $45 \cdot 9)$ \\
\hline Months of dialysis & $12(9 ; 12 \cdot 4$ to $18 \cdot 7)$ & $18(13 \cdot 5 ; 12 \cdot 9$ to $31 \cdot 6)$ \\
\hline Donor age (years) & $37(14 ; 31.8$ to 40$)$ & $39 \cdot 5(19 ; 24 \cdot 2$ to $45 \cdot 1)$ \\
\hline Total ischaemic time (hours) & $23.37(4.82 ; 20.9$ to 33.8$)$ & $23.65(3.2 ; 20 \cdot 2$ to $26 \cdot 4)$ \\
\hline $\begin{array}{l}\text { Serum calcium }(\mathrm{mmol} / \mathrm{l}) \\
\text { S }\end{array}$ & $2.41(0.11 ; 2.34$ to 2.44$)$ & $2 \cdot 49(0 \cdot 12 ; 2 \cdot 32$ to $2 \cdot 7)$ \\
\hline Inorganic phosphate $(\mathrm{mmol} / \mathrm{l})$ & $1.89(0.22 ; 1.84$ to 2.06$)$ & $2 \cdot 17(0.24 ; 1.95$ to 2.43$)$ \\
\hline Recipient sex (male) & 40 & 14 \\
\hline \multicolumn{3}{|l|}{ Mode of dialysis: } \\
\hline Haemodialysis & 40 & 14 \\
\hline Continuous ambulatory peritoneal & & \\
\hline dialysis & 26 & 4 \\
\hline \multicolumn{3}{|l|}{ Regrafts: } \\
\hline Second & 11 & 3 \\
\hline Third & 2 & 0 \\
\hline \multicolumn{3}{|l|}{ Calcium channel blockers: } \\
\hline Nifedipine & 13 & 1 \\
\hline Diltiazem & 22 & 6 \\
\hline
\end{tabular}

No significant differences by Mann-Whitney $\mathrm{U}$ test or $\chi^{2}$ test. accelerated rejection. There were no significant differences between the immediate and delayed function groups in terms of recipient and donor variables (table). Serum calcium and phosphate concentrations were not significantly different, although the phosphate concentrations seemed to be higher in the delayed function group. Seventy two patients either had raised concentrations of intact parathyroid hormone or had previously had a parathyroidectomy $(n=3)$. Fourteen patients had parathyroid hormone values within the normal range at the time of transplantation, and eight of these had delayed function.

The patients with delayed graft function had significantly lower concentrations of parathyroid hormone (median 5.9, quartile deviation $9 \cdot 1,95 \%$ confidence interval 5.8 to $32.4 \mathrm{pmol} / \mathrm{l}$ ) than those with immediate function (median 25.9, quartile deviation $21 \cdot 8,95 \%$ confidence interval $31 \cdot 4$ to $52 \cdot 1 \mathrm{pmol} / \mathrm{l}$ ) $(\mathrm{p}=0.0018 ;$ Mann-Whitney U test).

\section{Comment}

This study has shown for the first time an association between delayed renal allograft function and low concentrations of circulating parathyroid hormone in recipients at the time of transplantation. This finding contrasts with a retrospective study by Varghese $e t$ al, who noted a relation between delayed function and high concentrations of parathyroid hormone.

There were important differences between the two studies. The assay used by Varghese et al was an immunoassay for $\mathrm{C}$ terminal parathyroid hormone, which detects inactive fragments of the molecule that are normally excreted by the kidney, as well as the intact hormone. This assay poorly reflects the biological activity of parathyroid hormone. The values obtained are more closely associated with duration of chronic renal failure and the degree of residual renal function. Information relating to the duration of dialysis before transplantation was not included by Varghese et al. The delayed function rate in our study was lower (21\% compared with $46 \%)$ despite a less rigorous definition of delayed function (the requirement for dialysis)

Parathyroid hormone has been shown to have a vasodilatory action in various organs including the kidney. ${ }^{3}$ The vasodilator effect seems to be an intrinsic property of parathyroid hormone ${ }^{4}$ and to reside in the 24-28 amino acid fragment of the molecule whereas the calcaemic effect is a property of the $2-28$ segment. ' We have noted that parathyroid hormone has a renal vasodilator effect in cyclosporin treated rats (unpublished observations).

Parathyroid hormone may act as a vasodilator and 